\title{
Redesign the Plant layout for Efficiency Improvement and Cost Reduction: A Case Study
}

\author{
Belachew Mebrat $^{1}$, Lijalem Assefa ${ }^{2}$, Teshale Gezehagan ${ }^{3}$, Gedefaye Achamu ${ }^{4}$, K.Balasundaram ${ }^{5}$ \\ ${ }^{1}$ Lecturer in Industrial Engineering, Gondar Institute of Technology, University of Gondar, Ethiopia \\ ${ }^{2}$ Team Leader in, Mota Town Industry, Ethiopia \\ ${ }^{3}$ Team Leader in Kiya Natural Purified Water Bottling Factory, Ethiopia \\ ${ }^{4-5}$ Lecturer in School of Mechanical and Industrial Engineering, Dire Dawa Institute of Technology, Dire \\ Dawa University, Ethiopia
}

\begin{abstract}
In a global market the manufacturing industries have to minimized the production cost and improve the efficiency. The effective design of plant layout can significantly minimized the operational costs of manufacturing companies. An adequate plant layout design can improve the performance of the production line, their flexibility, efficiency. Proper plant layout design is one of the keys of success in factory management. In this study ongoing production process layout are studied and a new layout will be developed to improve the efficiency and reduce the production cost. The major problem faced by the workshop is high flow intensity between machines which have high interrelationship. This leads to high travelling time and high travelling cost. Two alternative layouts are developed by using Systematic Layout Planning, which is a systematic way of generating layout alternatives. The alternative layout involves transferring the machines which have high interrelationship close to each other. The alternative layouts are evaluated using weighting placement value (WPV) and placement rating $(P R)$ in Computerized Relationship Layout Planning (CORLAP) algorithm. The best alternative is chosen based on the performance measures which have the most significant improvement, total travel distance, total travel time, total travel cost, number of cross-over, output, average resource utilization, total average WIP level, total average waiting time and total time spent in the system. The constructed layout of the workshop efficiency is 30.16\% while the alternative 1 and alternative 2 layouts is $71.4 \%$ and $73 \%$ respectively. The annual production saving cost of the alternative layout is 34,982 birr.
\end{abstract}

Key Words: Plant layout, layout redesign, Workflow, Efficiency improvement.

\section{INTRODUCTION}

Productivity improvement is doing the things in the right and better way and makes it a part of continuous process. Therefore it is important to adopt efficient productivity improvement technique so as to ensure individuals and organization's growth in productivity. Lean manufacturing, facility layout planning, total quality management, production planning and control are a philosophy that maximize efficiency, reduces costs, improve product quality, and also take how to improve the workers safety. In a nutshell, lean manufacturing is a philosophical and methodological approach that strives to provide ever increasing value to the customer through total employee involvement in the reduction of non-value-added activities and their associated costs and facility layout is an arrangement of everything needed for production of goods or delivery of services. The next philosophy total quality management is the management approach of an organization centered on quality, based on the participation of all its members and aiming at long time success through customer satisfaction, and benefits to all members of the organizations and to society. The other improvement of productivity is Production planning and control. It is the process, which combines and transforms various resources used in the production/operations subsystem of the organization into value added product/services in a controlled manner as per the policies of the organization. Facility layout is the arrangement of operations, machinery and spaces and the correlation between them. It is the study of spatial allocation, for instance architecture space planning, manufacturing layout, offices layout and very-large-scale integration layout. Well-organized machine or department arrangements and suitable transportation paths create an efficient plant. Systematic Layout Planning (SLP) is a prominent procedural approach and is widely used in layout design for various small and medium enterprises. Gemal rogora general mechanical workshop is found in Dire Dawa in shell sub city next to samrat hotel. Its area covers $1200 \mathrm{~m}^{2}$ and it has 12 machines. These are crank shaft machine, two lathe machine, milling machine, ejection machine, facing machine, smoothing machine, drilling machine, hydraulic press, Banko boring, welding machines and cylinder boring machines are available. The main products of the workshop are gear, tread, cylinder 
block and shaft. The manufacturing process of the workshop is making to order. The existing system of the workshop is a type of assembling line but the manufacturing system is job-shop (process layout). The study works to design those machines of the workshop layout computer relationship layout planning to minimize the employee fatigue, reduce time consumption, effective space utilization, reduce material handling cost, and remove unnecessary machines in order to increase the productivity.

\section{LITERATURE REVIEW}

Many researchers have been done in facility planning area. Effective facility planning can reduce significantly the operational costs of a company by 10-30\%. Proper analysis of facility layout design could result in the improvement of the performance of production line. This can be realized by optimizing the capacity of a bottleneck; minimizing material handling costs; reducing idle time; maximizing the utilization of labor, equipment and space. Facility planning is an overall approach concerned with the design, layout and incorporation of people, machines and activities of a system. Huang emphasizes that facility layout design defines how to organize, locate, and distribute the equipment and support activities in a manufacturing facility to accomplish minimization of overall production time, maximization of operational efficiency, growth of revenue and maximization of factory output in conformance with production and strategic goals. Facility layout design has major influence on plant productivity. The purpose of layout design is to find the most effective facility arrangement and minimize the material handling. It has remained an active research area during recent decades (Allegri, 1984; Meller \& Gau, 1996; Tarkesh, Atighehchian, \& Nookabadi, 2009). Previous studies have shown that material handling cost has significant impact on plant's operating cost. According to American Society of Mechanical Engineers, Material handling is defined the art and science dealing with the movement, packaging and storing of substances in a form. The equipment used in material handling influences the productivity of manufacturing (Jiamruangjarus \& Naenna, 2016). It is estimated that material flow cost contributes from 30 to $70 \%$ of the total manufacturing cost, subject to the type of industry (Dongre \& Mohite, 2015; Immer, 1953; Matson, Mellichamph, \& Swaminathan, 1992). The operation cost during manufacturing can be reduced from 15 to $30 \%$ by well-organized material handling (Sule, 1994; Tuzkaya, Gülsün,Kahraman, \& Özgen, 2010). Thus, it is critical that the location of machines/workstations should be arranged in a way that reduces the distance travelled by personnel or material handling (Heragu, 1992). Most literature for layout design problem falls into two major categories, algorithmic and procedural approaches.

\subsection{Literature Summery}

The below selection criteria performed based on the Gemal rogora general mechanical work shop data observed. From type of layout used for this research job-shop layout and from the layout objective function used maximizing adjacency objectives. Past works like Amha Mulugeta's project are done by considering the workshop which has these types of layout. The procedures used in this research is systematic layout planning. It has the major advantage to know the necessary parameter clearly and measurement of materials movement due to this use systematic layout planning procedure. CRAFT method used departments which have equal area or which has common boundary. Pire wise exchange mostly used for equal area departments but also used unequal area. Pire wise must be used for departments less than five. It is better to work the construction algorithm rather than improvement. The existing system of the workshop is not constructed in layout consideration it seems like assembling line due to this workshop starts from scratch that is used construction algorithm which is CORLAP method.

\section{STATEMENT OF PROBLEMS}

Gemal Rogora general mechanical workshop is a type job shop process manufacturing industries. It has numerous business units where the problem area which happens in the workshop will be discussed here. The workshop has 12 machines while the machine installation of the Gemal Rogora general mechanical workshop is installing randomly and the Frequency of cross over is high between the machines. The Processes which have high interdependency are not located close to each other. This causes high travelling time for the operator as they have to travel from machines to machines. The labor cost of each product is also high due to high travelling cost. The manufacturing process of the product is a type of job-shop process but the machine installation of the work shop is a kind of assembling line this causes to increase the manufacturing costs, work process, lead time, and reduce productivity. Ineffective facility layout increases the production lead time, maximize the movement of worker, covers more production area, and decrease the flow of materials. Those reasons reduce the overall efficiency of the workshop and increase the overall production cost and material handling cost. The existing system of the Gemal Rogora general mechanical workshop have high amount of waste such as unnecessary motion from lathe machine to drilling machine and milling machine to drilling machine, excessive motion from raw material storage station to workstation, excessive transportation cost moving the materials from drilling to milling, lathe, crank shaft and welding machine, over processing due to moving the employee long distance specially welding machine to drilling machine, excessive set up time of each machine due to improper layout . Those wastes reduce the workshop productivity. There are numerous computerized layout planning algorithms to follow. Each of these algorithms possesses their distinguishing characters. Also, as discussed previously, the major divisions in layout planning are construction of new layout starting from blank and improving the current feasible layout. One algorithm from each of these 
divisions is selected and using that algorithm layout of GRGMW production layout is designed. Thus, the study does not attempt to use all computerized algorithms for layout design of GRGMW. Furthermore, to show the aid of computers in the layout problems, the case taken is only in GRGMW. Other companies can take the same procedure to arrive at their own effective layout. Aim of any organization is being effective and efficient productivity. It has the general and the specific objectives of the Study are described below. The main objective of the study is to design the production layout of the Gemal Rogora General Mechanical Workshop (GRGMW) in order to increase productivity, evaluating existing layout, generating alternative layout and compare the efficiency the existing layout with the alternative layout.

\section{RESEARCH METHODOLOGY}

The main objective of the facility design is to design effective workflow and to improve productivity of machines, material flow and workers in order to increase the workshop efficiency. Important of layout in mechanical workshop help in smooth functionality in operation and cost saving process, for functionality, better placed close important department and minimize working distance of the workshop and overall facility, improving including employee safety and communication and to make sustainable development to the future. The research methodology as shown in fig. 1.

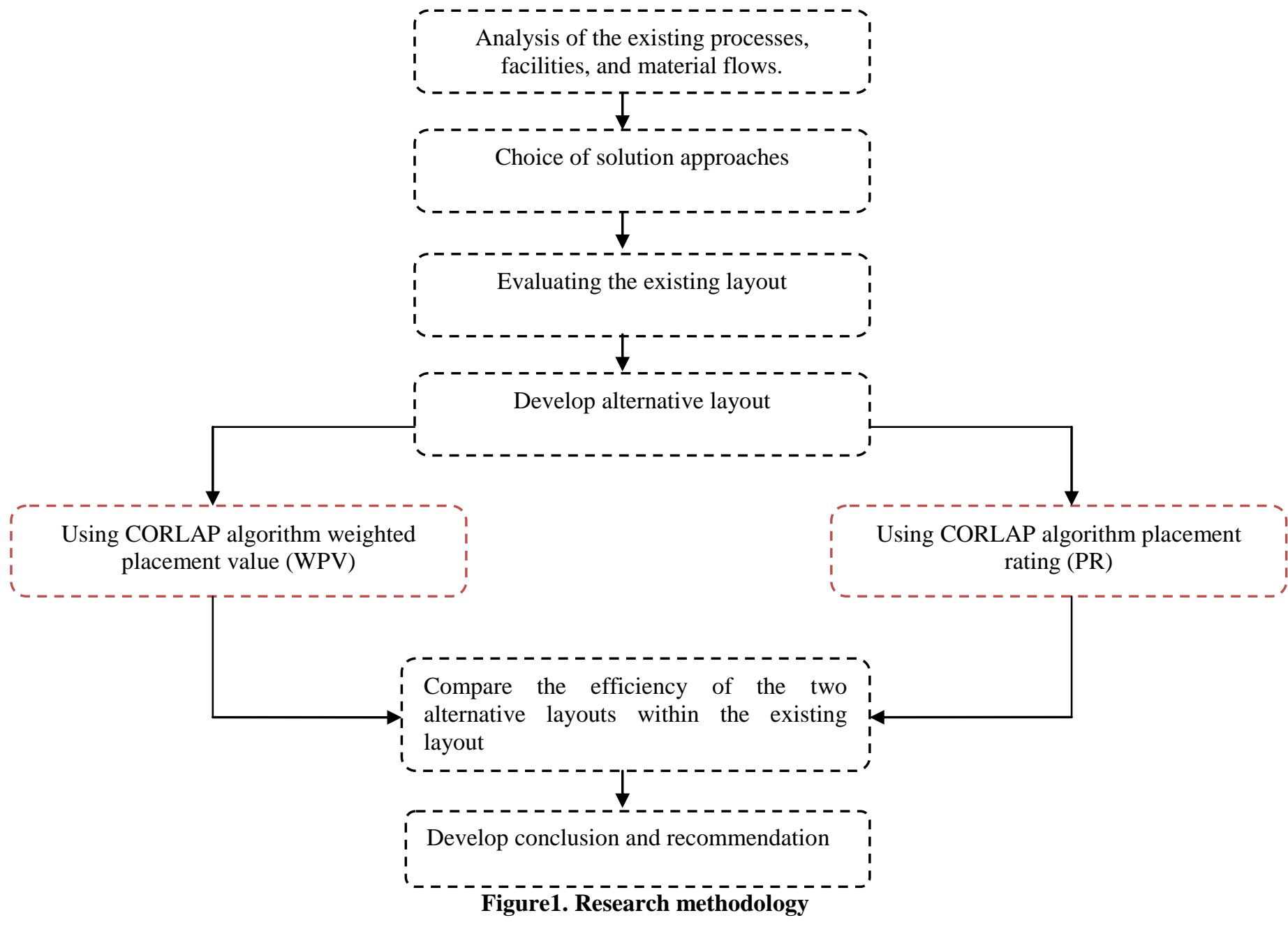

\section{RESULTS AND DISCUSSION}

Different scholars defines the procedures of facility layout selection those are immer's basic step said that good plant layout, means placing the right equipment, coupled with the right method, in the right place, to permit the processing of a product unit in the most effective manner, through the shortest possible distance and the shortest possible time, naddles Ideal System Approach is based on the hierarchical approaches of aim for the "theoretical ideal system", conceptualize the "ultimate ideal system", design the "technologically workable ideal system" and install the "recommended" the present system, reads Plant Layout Procedure apples Plant Layout Procedure and muther's Systematic Layout Planning (SLP). Basically there are three stages of systematic layout planning (SLP) this are 1) analysis under this gathering data, flow analysis, activity analysis, space availability and space requirement, 2) search under here Space relationship diagram, reasons to modify, restrictions and layout alternative 3) selection in this include evaluation. It requires an initial layout in addition to the input needed by the construction techniques. CRAFT 
(Computerized Relative Allocation of Facilities Technique) and MULTIPLE (MULTI-floor Plant Layout Evaluation) are popular improvement algorithms that uses pair-wise exchange (7), (8). Recently attentions have been focused on applying a Simulated Annealing approach to the layout problem. The great advantage of this is to avoid being caught in local optimal by sometimes accepting moves that worsen the objective function. CRAFT is representative of improvement type layout algorithm. It is more popular than the other computer based layout procedures. It is an improvement algorithm and Starts with an initial layout and proceeds to improve the layout by interchanging the department's pair wise to reduce the total material transportation cost. It does not give the optimal layout; but the results are good and near optimal, which can be later corrected to suit the need of the layout Planner. CRAFT used for departments which have equal area and common boundary. This algorithm is characterized by efficiently allocating the departments in heuristic way. Under the criterion of minimizing the material handling costs for multiple product items, where this cost is expressed as a linear function of the transportation distance. Basically, CRAFT seeks an optimum design by sequentially improving the layout, based upon material flow analysis, as given in an initial layout specified as either an existing layout or a predetermined spatial array.

\subsection{CORELAP (Computerized Relationship Layout Planning)}

CORELAP is representative of the construction type of layout algorithm. It is concerned with generating a layout based upon closeness ratings determined from an activity relationship diagram. CORELAP expresses the interdepartmental relationships in a closeness relationship matrix, which is then used to construct a layout. It constructs layouts by locating rectangular shaped departments. The relationship chart provides the basis for the order in which different Departments are placed. The input data needed by CORELAP include is 1 . The number of departments $\mathrm{N}, 2$. The area of each department, 3. Activity relationship diagram for each department, and 4. Weights for activity relationships (which will be decided by the layout planner e.g. A=4, $\mathrm{E}=3$, $\mathrm{I}=2, \mathrm{O}=1, \mathrm{U}=0$ and $\mathrm{X}=-1$ ). The closeness rating between departments $\mathrm{i}$ and $\mathrm{j}$ is based upon the weight assigned to the activity relationship between the two departments.

\subsection{Data collection}

To develop optimal layout we must clearly identify the problem of the GRGMW and proposed solutions for those problems. The data which we are collected for this study area of each machine, layout of the workshop is process (job-shop), the production system is make to order and the main products is cylinder block, shaft, gear and thread. To produce these products different machines and processes are used. The cylinder block is used to boring cylinders with the required radius. However the next machine hydraulic press is used to remove the wear out cylinder from the motor and shafts. The main machines in the workshop lathe 1 or 2 are used for doing many activities. These are making treads, facing, turning, gears and others. The other smoothing is used for smoothing the, cylinders, gears, shafts and others. The function of drilling is boring the shafts, making holes, minimizing weight of the shafts and associated operations and the welding is used for aligning and filling worn-out materials and tools. The existing layout of the workshop as shown in figure 2 below it is a type of assembling line and also installed without the production relationship. The number represents the distance $b / n$ machines, length and width of machines.

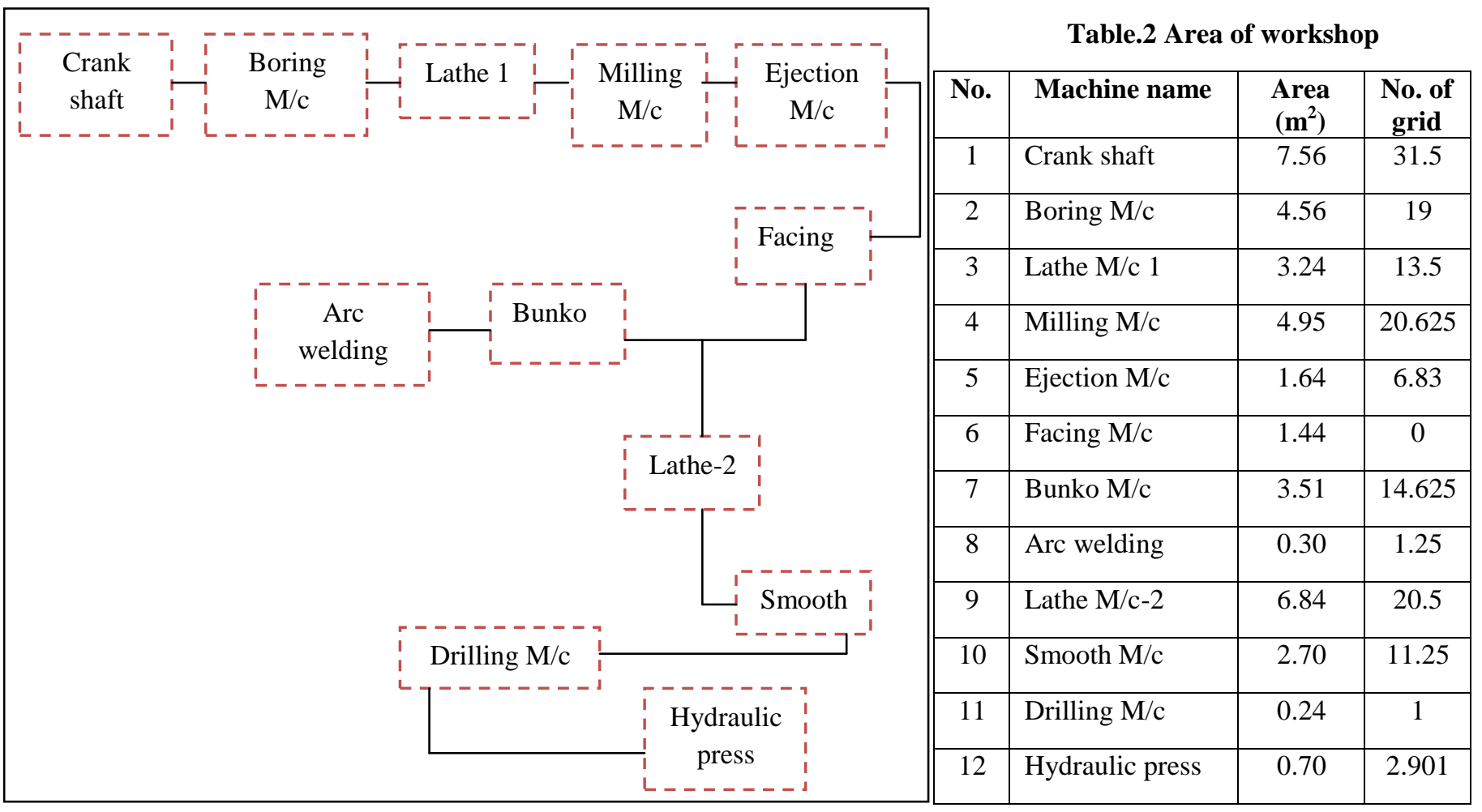


Figure 2. Existing layout of the workshop

To find the number of grid using the department area $0.24=1$ how much is for $7.56 \mathrm{~m}^{2}$, we can get 31.5 number of grip like this evaluate all machines. The annual production flow used to determine the relationship between machines. Based on this develop the relationship diagram. For example the workshop produce 10 treads per week the production sequence is flows from arc welding to lathe 1 machine. Since there are 52 weeks in a year, annual production flow of tread is 520 . In the same way the production flow from crank shaft to lathe 1 welding to lathe 1 is 52 . All other flow of production of the workshop is continued in such a way. As we located annual production from to chart flow in table 3 develop the relationship diagram. Based on the unequal area of the machines and have not common boundary between them it is better to select construction algorithm rather improvement. From construction select COREAP to insure maximizing adjacency score of the departments in order to reduce the material handling cost. Finally the benefit obtained from the constructed layout will be compared with the currently being used layout to draw conclusions and recommendations.

Table 3. From to char production flow relationship

\begin{tabular}{|c|c|c|c|c|c|c|c|c|c|c|c|c|}
\hline & $\begin{array}{c}\text { Crank } \\
\text { shaft }\end{array}$ & $\begin{array}{c}\text { Boring. } \\
\text { M/c }\end{array}$ & $\begin{array}{c}\text { Lathe } \\
\text { M/c }\end{array}$ & $\begin{array}{c}\text { Milling } \\
\text { M/c }\end{array}$ & $\begin{array}{c}\text { Ejection } \\
\mathrm{M} / \mathrm{c}\end{array}$ & $\begin{array}{c}\text { Facing } \\
\mathbf{M} / \mathbf{c}\end{array}$ & $\begin{array}{c}\text { Bunko } \\
\text { M/c }\end{array}$ & $\begin{array}{l}\text { Arc } \\
\text { Wel. }\end{array}$ & $\begin{array}{c}\text { Lathe2 } \\
\text { M/c }\end{array}$ & $\begin{array}{c}\text { Smooth } \\
\text { M/c }\end{array}$ & $\begin{array}{l}\text { Drill } \\
\text { M/c }\end{array}$ & $\begin{array}{l}\text { Hyd. } \\
\text { press }\end{array}$ \\
\hline $\begin{array}{l}\text { Crank } \\
\text { shaft }\end{array}$ & & & 52 & 38 & & 66 & & 42 & 32 & & 72 & \\
\hline $\begin{array}{l}\text { Boring } \\
\text { M/c }\end{array}$ & & & & & 84 & & & & & 242 & & \\
\hline $\begin{array}{l}\text { Lathe } \\
\text { M/c } 1\end{array}$ & & & & 278 & & 295 & & 520 & & 351 & 364 & 256 \\
\hline $\begin{array}{l}\text { Milling } \\
\text { M/c }\end{array}$ & & & & & & & 112 & 82 & 104 & 48 & 168 & 24 \\
\hline $\begin{array}{l}\text { Ejection } \\
\text { M/c }\end{array}$ & & & & & & & & & & & & \\
\hline $\begin{array}{l}\text { Facing } \\
\text { M/c }\end{array}$ & & & & & & & & & 156 & & 188 & \\
\hline $\begin{array}{l}\text { Bunko } \\
\text { M/c }\end{array}$ & & & & & & & & 48 & & 78 & 56 & 260 \\
\hline $\begin{array}{l}\text { Arc } \\
\text { welding }\end{array}$ & & & & & & & & & & 220 & 186 & \\
\hline $\begin{array}{l}\text { Lathe } \\
\text { M/c-2 }\end{array}$ & & & & & & & & & & & 140 & 312 \\
\hline $\begin{array}{l}\text { Smooth } \\
\text { M/c }\end{array}$ & & & & & & & & & & & 132 & \\
\hline $\begin{array}{l}\text { Drilling } \\
\text { M/c }\end{array}$ & & & & & & & & & & & & \\
\hline $\begin{array}{l}\text { Hydraulic } \\
\text { press }\end{array}$ & & 156 & & & & & & & & & & \\
\hline
\end{tabular}

The constructed relationship diagram developed based on the existing layout assembling line. If the departments which are assemble near to each other and if they are parallel, there is relation between them and if no there is no relationship as shown in figure 3 .

Table.3 Systematic layout percentage rating and Rating value

\begin{tabular}{|c|c|c|}
\hline Rating & $\begin{array}{c}\text { Percentage } \\
\text { Ratio (\%) }\end{array}$ & $\begin{array}{c}\text { Range of } \\
\text { rating }\end{array}$ \\
\hline A & 5 & $>350$ \\
\hline E & 10 & {$[350-240)$} \\
\hline I & 15 & {$[240-110)$} \\
\hline O & 20 & {$[110-24)$} \\
\hline U & 50 & $<24$ \\
\hline
\end{tabular}




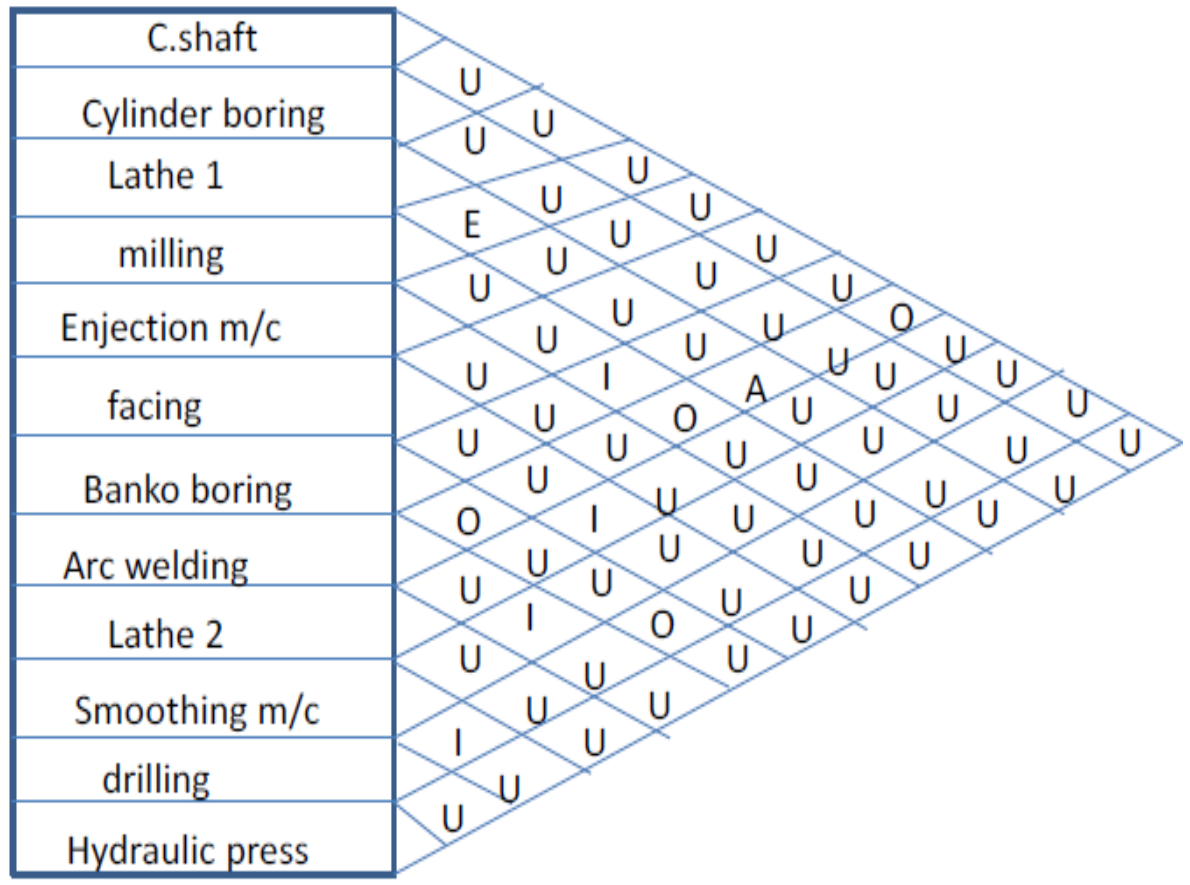

Figure 3. The constructed layout relationship diagram

Table 3 shows the number of products that are transported between the machines. Based on the quantity of transported material between machines table 2 from-to chart, the activity relationship analysis is made. It is built by considering the quantity of material transported between any two sections. For the analysis the closeness ratings (A, E, I, O, U and X) are assigned for the relation between the twelve sections. The activity relationship chart is then drawn by giving A rating for high material flow and $\mathrm{U}$ for least or no material flow between sections. For example arc welding and lathe 1 sections are known to have high volume of products being transported between them (sum 520). Thus the highest ranking (A) is given for their relation. Other Interdepartmental relationships having less material flow between them are given $U$ rating signifying there is undesirable closeness necessity. Based on the existing layout relationship diagram evaluate the total closeness rating value for $\mathrm{A}=4$, for $\mathrm{E}=3$, for $\mathrm{I}=2$, for $\mathrm{O}=1$ and for $\mathrm{U}=0$. Then sequenced the departments the first department is selected based on the highest TCR the second department is selected based on the highest relationship with the departments which is selected first if tie exist sequence in comparing the TCR value the next department is this procedure until all departments are sequenced. The constructed layout sequence is 3-4-6-8-7-10-1-9-11-2-5-12. The score of the constructed layout for upper triangular matrix is 19 and for symmetry matrix is $2 * 19=38$. The total closeness rating is evaluated using the annual production flow of workshop order from the customer that is 126 evaluating.

\subsection{Developing Alternative Layout}

The methods are used to developing the alternative layout are: 1) Using CORLAP algorithm by weighting placement value (WPV) 2) Using CORLAP algorithm by placement rating (PR). The relationship diagram is developed using the workshop annually production flow from one section to the other sections as we seen from -to chart data collection. All ratings have been included in the activity relationship chart to have a fair distribution of the ratings. One rule of thumb to follow in assigning the ratings is to have all the values in the chart $\mathrm{A}$ and $\mathrm{E}$ ratings should have low percentage than the others around $5 \%$ and $10 \%$ respectively. I and $\mathrm{O}$ should have $15 \%$ and $20 \%$ and $\mathrm{U}$ rating should have more than $50 \%$ of the rating value.

Table4. Rating percentage in activity relationship chart

\begin{tabular}{|c|c|c|}
\hline Rating & $\begin{array}{c}\text { Available } \\
\text { No. in chart }\end{array}$ & $\begin{array}{c}\text { Percentage } \\
\text { \% }\end{array}$ \\
\hline A & 3 & 4.5 \\
\hline E & 6 & 9.09 \\
\hline I & 10 & 15.15 \\
\hline O & 13 & 19.69 \\
\hline U & 34 & 51.5 \\
\hline
\end{tabular}




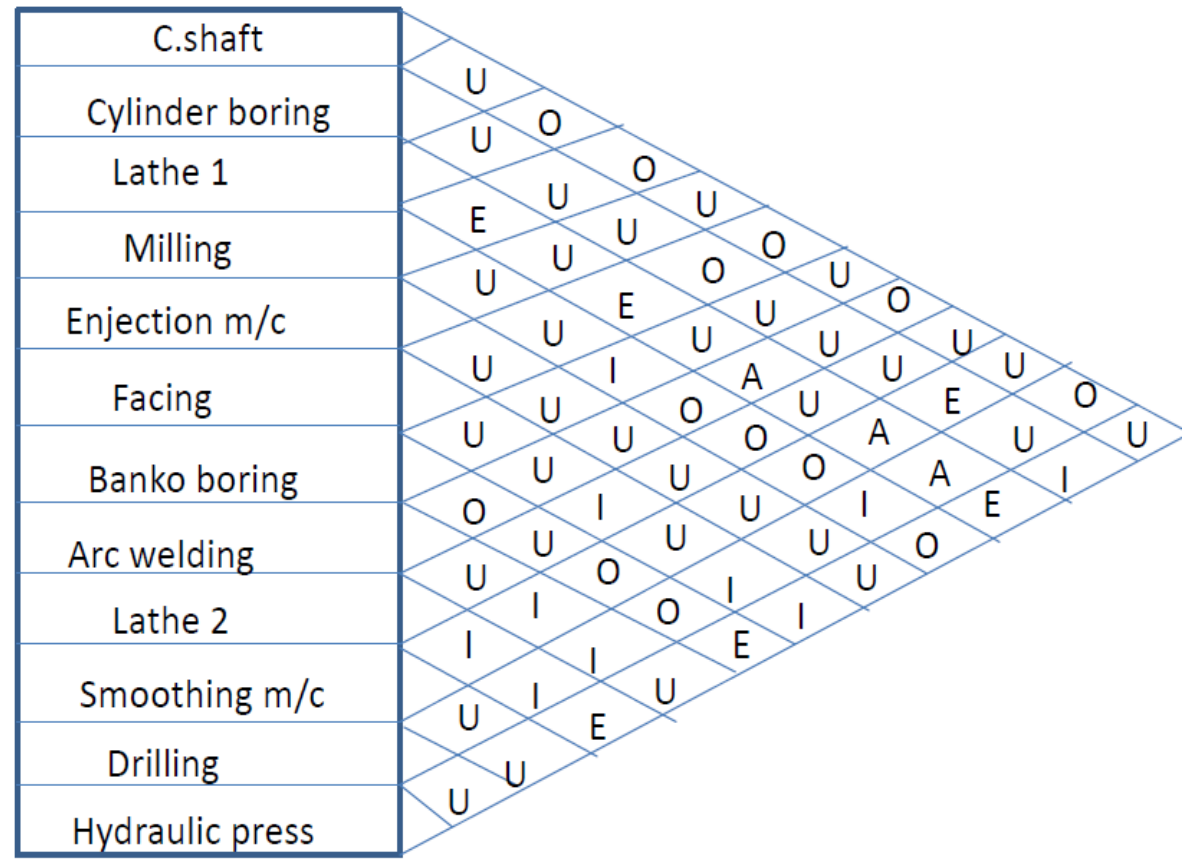

Figure 4. Relationship chart based on annual production flow

Based on the activity relationship chart shown above activity relationship diagram has been drawn. This diagram clearly shows the closeness necessity between different sections. From the figure 4 we can see that arc welding and lathe 1 has high closeness rating. They are given A rating and are close to one another in the current layout. High volume of material that is transported between these sections will not be required to travel long distance. The same is true for lathe1 and hydraulic press. They are placed near to each other while having an E rating. on the other hand materials flows from milling to Ejection machine of the GRGMW has unimportant relationship as we see the above but the installation of the existing layout is very near this leads to high distance movements for other departments which have high relation departments as result the workshop decreases the productivity. WPV alternative layout is based on the fully adjacency and touching based algorithm by taking a half weight of touching and one weight of fully adjacent. Let as put at the center and we will have eight adjacent for the first department as follow. The numbering from 1-8 is labeled counter-clockwise starting at the left west corner and the best placement is the smallest number with greatest WPV. To evaluate the layout we design by calculating the efficiency using scores of the layout and the relationship diagram closeness rating. Take if the designed layout is touched fully or partially put 1 if not touch put 0 and then evaluate the score using their relationship. Use $A=4, E=3, I=2, O=1, U=0, X=-1$. The score of the layout is as follow and we must double it as it is obtained only from the upper triangle of the matrix. The comparation between the existing layout and the alternative layout as shown in the table 5 . 

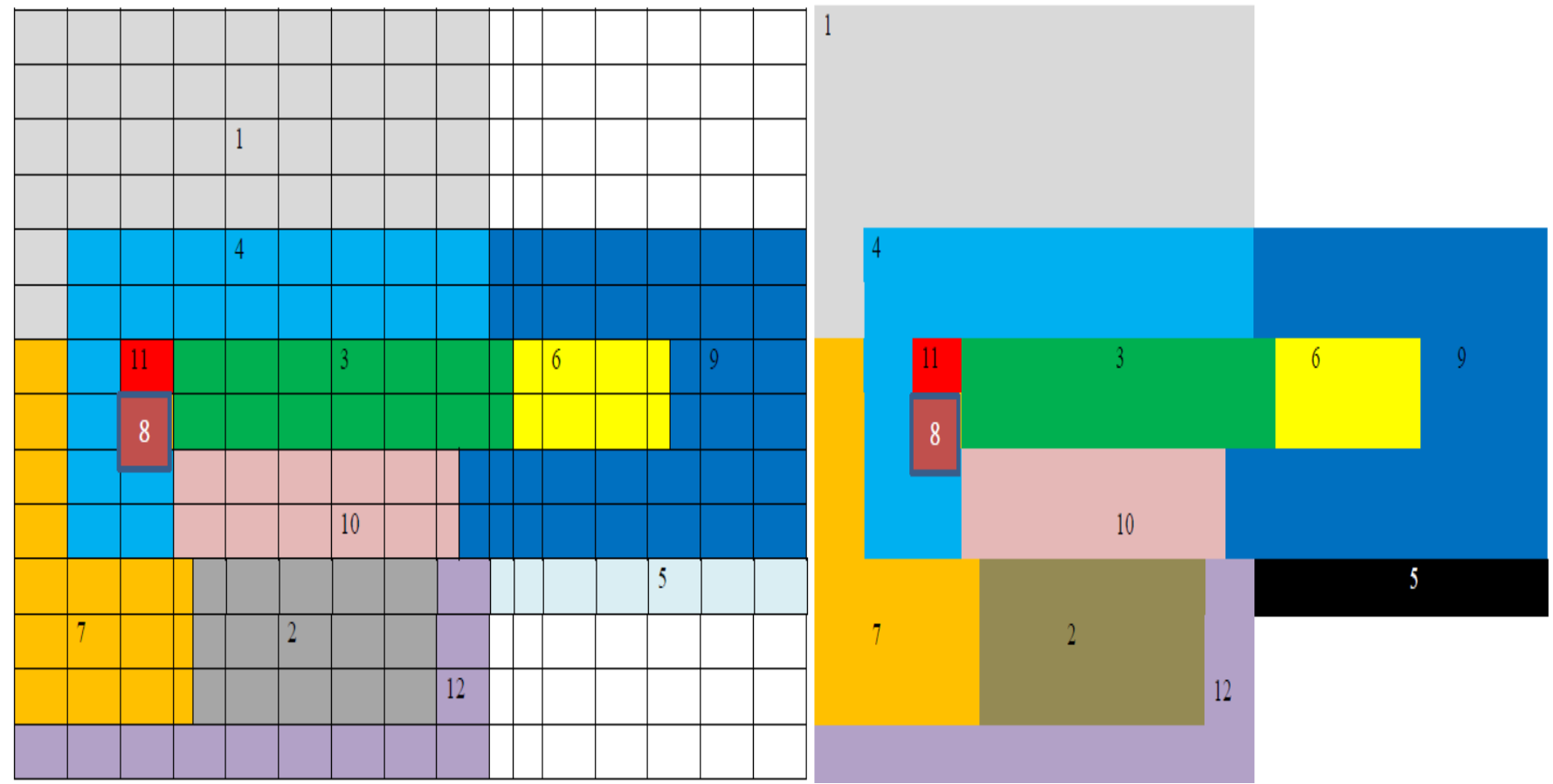

Figure 5. Alternative layout diagram of the workshop

The length and the width of the machines are known in the data collection chapter. From this alternative layout evaluate the distance matrix. The main parameter used to calculate the cost of the product is annual flow of the production, unit product transport cost and distance between machines. The main product of the workshop is cylinder block, shaft, thread and gear and the sequence of Cylinder block: hydraulic press-lathe 2-haydrolic press -cylinder boring, shaft: lathe 1- drilling -lathe 1, gear: lathe 1milling - lathe 1-drilling and the sequence of thread is arc welding to lathe 1 .

Table 5 Comparation between existing and alternative layout

\begin{tabular}{|l|l|l|l|}
\hline \multicolumn{1}{|c|}{ Comparation parameter } & $\begin{array}{c}\text { Existing } \\
\text { layout }\end{array}$ & $\begin{array}{c}\text { Alternative } \\
\text { layout }\end{array}$ & $\begin{array}{c}\text { Saving cost } \\
\text { per year(Birr) }\end{array}$ \\
\hline Efficiency & $30.16 \%$ & $73 \%$ & \\
\hline Annual material handling cost of cylinder block & 10,267 & 2,725 & 7,542 \\
\hline Annual material handling cost of shaft & 5,489 & 1,192 & 4,297 \\
\hline Annual material handling cost of gear & 12,019 & 3,565 & 8,454 \\
\hline Annual material handling cost of thread & 16,688 & 1,999 & 14,689 \\
\hline Total annual material handling saving cost per year & & & $\mathbf{3 4 , 9 8 2}$ Birr \\
\hline
\end{tabular}

\section{CONCLUTION}

Layout planning problem is one of the main factors that play the great role in the effectiveness of manufacturing and service industries. After careful analysis of the current layout analysis of the GRGMW and CORLAP algorithm the following conclusions are made. The constructed layout using existing assembling line of the gemal rogora general mechanical workshop is less efficient in that it incorporates many back and forth movements of the parts to be produced. These are further amplified by the location of sections as well as machines having high interaction far apart from one another. For example lathe 1 machines and arc welding, lathe 1 machine and smoothing machine, drilling with lathe 1 machines having high volume of product being transported between them but they are placed far from one another in the current layout of the workshop. Furthermore, wasting the workshop time and resource in transporting high volume of materials through long distances, the planned production volume as well as profit could not be attained. Designing a better layout for GRGMW manufacturing shop floor is thus reasonable and mandatory. After the 
current layout has been analyzed, two different alternative new layouts have been developed. First the current layout of sections in the workshop has been evaluated using Computerized Relative Allocation of Facilities Technique (CORLAP) algorithm. Then develop the alternative layout using annual production volume. From two type of design layout the workshop select the high adjacency score has been attained that alternative layout score is 92 . The efficiency of the constructed layout is $30.16 \%$ and the efficiency of the designed layout using weighting placement value is $71.4 \%$ and also the efficiency of the alternative layout using placement rating is $73 \%$ in order to maximize the workshop productivity, reduce the worker fatigue, effective space utilization and reduce the transporting cost the workshop must choose the highest efficient layout. This study thus has forwarded a layout which is better than the existing one. The annual material handling cost of the alternative layout is less than the existing layout. The annual material handling saving cost is 34,982 birr therefore the alternative layout is most economical and would bring sustainable productivity.

\section{REFERENCES}

[1]. Priyanka Yadav, Suman Sharma "To compare production efficiency of manual plant layout and computerized plant layout using ARENA software," international journal of engineering research and general science volume 4, issue 4, july-august, 2016.

[2]. Sanjeev .B. Naik ; Dr. Shrikant Kallurkar, “A literature review on efficient plant layout design”. (IJIERD) volume 7; Issue 2 ; may -august 2016.

[3]. Daniel Back, Peter Johansson. "Effective development of plant layout and material handling system” September 2006.

[4]. W. Wiyaratn, A. Watanapa, and P. Kajondecha. "Improvement plant layout based on systematic layout planning". INCSIT, vol.5, No.1, February 2013.

[5]. W. Wiyaratn and A. Watanapa, "Improvement plant layout using systematic layout planning (SLP) for increased productivity," in Proc World Academy of Science, Engineering and Technology, vol. 36, pp. 269-273, December 2010.

[6]. Riyad H., Kamruzzaman R., Subrata T., Increasing productivity through facility layout improvement using systematic layout planning pattern theory, Global Journal of Researches in Engineering: J - General Engineering 2014.

[7]. Naik B.S., Kallurkar S., A literature review on efficient plant layout design, International Journal of Industrial Engineering Research and Development 2016 